\title{
Formulation of Ceftriaxone Conjugated Gold Nanoparticles and Their Medical Applications against Extended-Spectrum $\beta$-Lactamase Producing Bacteria and Breast Cancer
}

\author{
Sanaa M. F. Gad El-Rab ${ }^{1,2 *}$, Eman M. Halawani ${ }^{3}$, and Aziza M. Hassan ${ }^{1,4}$ \\ ${ }^{1}$ Department of Biotechnology, Faculty of Science, Taif University, P.O. Box 888, Taif, 21974, Saudi Arabia \\ ${ }^{2}$ Department of Botany and Microbiology, Faculty of Science, Assiut University, 71516 Assiut, Egypt \\ ${ }^{3}$ Division of Microbiology, Department of Biology, Faculty of Science, Taif University, P.O. Box 888, Taif, 21974, Saudi Arabia \\ ${ }^{4}$ Cell Biology Department, National Research Centre, 33 El-Bohooth Street, Dokki, Giza, Egypt
}

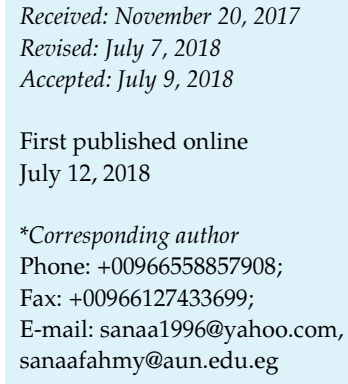

pISSN 1017-7825, eISSN 1738-8872

Copyright@ 2018 by

The Korean Society for Microbiology and Biotechnology
Gold nanoparticles (AuNP) and their conjugates have been gaining a great deal of recognition in the medical field. Meanwhile, extended-spectrum $\beta$-lactamases (ESBL)-producing bacteria are also demonstrating a challenging problem for health care. The aim of this study was the biosynthesis of AuNP using Rosa damascenes petal extract and conjugation of ceftriaxone antibiotic (Cef-AuNP) in inhibiting ESBL-producing bacteria and study of in vitro anticancer activity. Characterization of the synthesized AuNP and Cef-AuNP was studied. ESBLproducing strains, Acinetobacter baumannii ACI1 and Pseudomonas aeruginosa PSE4 were used for testing the efficacy of Cef-AuNP. The cells of MCF-7 breast cancer were treated with previous AuNP and Cef-AuNP at different time intervals. Cytotoxicity effects of apoptosis and its molecular mechanism were evaluated. Ultraviolet-visible spectroscopy and Fourier transform infrared spectroscopy established the formation of AuNP and Cef-AuNP. Transmission electron microscope demonstrated that the formed nanoparticles were of different shapes with sizes of 15 35 $\mathrm{nm}$ and conjugation was established by a slight increase in size. Minimum inhibitory concentration (MIC) values of Cef-AuNP against tested strains were obtained as 3.6 and $4 \mu \mathrm{g} / \mathrm{ml}$, respectively. Cef-AuNP demonstrated a decrease in the MIC of ceftriaxone down to more than 27 folds on the studied strains. The biosynthesized AuNP displayed apoptotic and time-dependent cytotoxic effects in the cells of MCF-7 at a concentration of $0.1 \mu \mathrm{g} / \mathrm{ml}$ medium. The Cef-AuNP have low significant effects on MCF-7 cells. These results enhance the conjugating utility in old unresponsive ceftriaxone with AuNP to restore its efficiency against otherwise resistant bacterial pathogens. Additionally, AuNP may be used as an alternative chemotherapeutic treatment of MCF-7 cancer cells.

Keywords: Ceftriaxone conjugated gold nanoparticles, antimicrobial activity, extended spectrum $\beta$-lactamase (ESBL) producing bacteria, MCF-7 Cells, MTT assay

\section{Introduction}

Respiratory tract infections (chronic and acute) are a result of inappropriate antimicrobial agents. These agents lead to resistance development and the opportunistic emergence of bacterial pathogens that substitute indigenous microorganisms [1]. Acinetobacter baumannii (A. baumannii) bacteria and Pseudomonas aeruginosa (P.aeruginosa) bacteria belong to the ESKAPE pathogens group (Enterococcus faecium, A. baumannii, P. aeruginosa, Klebsiella pneumoniae, Enterobacter species, and Staphylococcus aureus) that are common causes of life-threatening nosocomial infections among immune-compromised and critically ill patients [2]. The occurrence of the ESBL is suspected in A. baumannii 
and $P$. aeruginosa diseases when resistance to one or more than one of the extended-spectrum cephalosporins (ESC) (ceftriaxone, cefotaxime, cefepime or ceftazidime) [3, 4]. The production of ESBL has become increasingly prevalent among P.aeruginosa and A.baumannii [5-7]. The ESBL enzymes cause inactivation of the antibiotics aztreonam, cephalosporins, penicillins and the $\beta$-lactamase inhibitors, which limits the number of effective antibiotics for treatment $[3,4]$. The studies on risk factors for infectious diseases due to ESBL-producing A. baumannii and P. aeruginosa are limited and have been related to respiratory tract infections [8,9].

The application of nano-materials in activating pathogens is in virtue of the inability of such agents to induce resistance in bacteria. Also, nanotechnology appears to have a key role in treating different metabolic and pathological disorders including tumors, HIV, liver diseases, arthritis and inflammation, in addition to having other modern medicinal applications [10, 11]. Recently, the biosynthesis of metal nanoparticles (MNP) with novel, eco-friendly, and non-toxic, convenient plant extracts [12] is under much study. In MNP biosynthesis, the active biogenic functional groups of plant extract play a key role by acting as biological reducing, capping, and stabilizing agents [13]. The biosynthesized MNP can also have reduced toxicity, enhanced biocompatibility and stability, mainly due to coating them with capping agents or biogenic surfactants. The biosynthesized nanoparticles are used in medicinal applications, which contain drug delivery, disinfection, an anticancer agent, imaging, and tissue repair [10]. The AuNP appear to have countless cancer treatment effects due to their amazing interactions on the surface of cancer cells [14]. Because of nontoxicity and non-immunogenicity, AuNP are ideal for drug delivery preparation. Also, AuNP act as an excellent potential vehicle and are highly attractive for are the drug delivery applications due to their functionalization properties (plural) [15]. On the other hand, AuNP alone are believed to lack antibacterial efficiency; it can be conjugated with antibiotics to enhance antibacterial efficacy [16]. AuNP do not contain a reactive oxygen species (ROS) mechanism, although ROS damage is the purpose of cellular death stimulated by some bactericidal nano-materials and antibiotics [17].

Currently, there are no studies for using Cef-AuNPs to control ceftriaxone resistance against ESBL-producing bacterial strains $P$. aeruginosa PSU4 and A. baumannii ACI1 (as shown in Table 1). These strains were isolated and identified in our previous study[18]. Therefore, this study was designed to look for a new antimicrobial agent such as Cef-AuNP as a good alternative to the antimicrobial compounds of ESBL-producing bacteria. Also, this work is to assess the in vitro anticancer activity of biosynthesized AuNP and Cef-AuNP on MCF-7 breast cancer cells. Thus, the present study is an attempt to revive and turn an old ineffective drug into an effective drug against ESBLproducing bacterial pathogens using AuNP as a tool. To achieve the same, we synthesized AuNP, conjugated them with ceftriaxone, and performed characterization of these using UV-visible spectroscopy, Transmission Electron Microscopy, and Fourier transform infrared spectroscopy, followed by pertinent antibacterial efficacy and anticancer assays. The strategy summarized in the current study is expected to work as a scientific scaffold forming the basis on which a series of new nano-formulations meant for "reviving" old inefficient antibiotics into potent therapeutics could be designed.

\section{Materials and Methods}

\section{Bacteria and Growth Conditions}

$P$. aeruginosa PSU4 and $A$. baumannii ACI1 strains were obtained from our previous study [18]. These strains were ESBL positive and displayed complete resistance to antibiotic ceftriaxone. Before performing the antibacterial activity test, fresh inoculum of each bacterial strain was inoculated in nutrient broth medium and the culture was incubated at $37^{\circ} \mathrm{C}$ for $18 \mathrm{~h}$. However, turbidity of bacterial cells was detected with the nutrient broth to the common standard (i.e., $1.5 \times 10^{8} \mathrm{CFU} / \mathrm{ml}$ ).

\section{Preparation of Rosa damascenes Petal Extract}

The fresh and healthy Rosa damascenes petals were cleaned several times with MilliQ water until no foreign material remained.

Table 1. Resistance patterns of ESBL-producing bacteria.

\begin{tabular}{|c|c|c|c|}
\hline Names of isolates & Source & Accession number & Antibiotic resistance profiles \\
\hline Acinetobacter baumannii ACI1 & Sputum & LC325252 & $\begin{array}{l}\text { AK, AMP , AMC, CEC, FOX, FEP, CXM, CAZ, CRO, CTX, } \\
\text { CIP, LVX, DO, SXT, CN, MEM, TZP, IPM }\end{array}$ \\
\hline Pseudomonas aeruginosa PSE4 & Sputum & LC189106 & $\begin{array}{l}\text { AK, AMP, AMC, CEC, FOX, FEP, CXM, CAZ, CRO, CTX, } \\
\text { CIP, LVX, DO, SXT, CL, IPM, CN, MEM, CLR, TGC }\end{array}$ \\
\hline
\end{tabular}

AK, Amikacin; AMC, Amoxy/Clavulanic acid; CEC, Cefaclor; FEP, Cefepime; CTX, Cefotaxime; FOX, Cefoxitin; CAZ, Ceftazidime; CRO, Ceftriaxone; CXM, Cefuroxime; DO, Doxycycline/HCL; CIP, Ciprofloxacin; LVX, Levofloxacin; CLR, Clarthromycin; AMP, Ampicillin; MEM, Meropenem; SXT, Sulpha/Trimethoprim; TGC, Tigecycline; CN, Gentamicin; IPM, Imipenem; TZP, piperacillin-tazobactam; CL, Chloremphenicol. 
Twenty-five grams of petals were finely cut and stirred with $100 \mathrm{ml}$ of de-ionized water at $85^{\circ} \mathrm{C}$ for $20 \mathrm{~min}$. The petal extract was filtered with Whatman No. 1 filter paper and the filtrate was stored at $4^{\circ} \mathrm{C}$ for further experiments as reducing agent and stabilizer, being usable for within 2 weeks [19].

\section{Biosynthesis of AuNP}

Rosa damascenes petal extract was prepared as above. Five $\mathrm{ml}$ of petal extract was added drop-wise into $50 \mathrm{ml}$ of $1 \mathrm{mM}$ aqueous solution of $\mathrm{HAuCl}_{4}$ with constant stirring at different temperatures and different $\mathrm{pH}$. The color change was monitored [20]. After complete incubation, the AuNP were collected by centrifuge at $15,000 \mathrm{~g}$ for $30 \mathrm{~min}$ and washed with de-ionized water. However, $50 \%$ ethanol was used to remove excess petal extract from the nanoparticles and the AuNP sample was kept at room temperature until further characterization.

\section{Conjugation of Ceftriaxone with Gold Nanoparticles}

In our study, ceftriaxone conjugated gold nanoparticles (CefAuNP) were synthesized in a two-stage procedure. The previous method for synthesis of AuNP considered the first stage procedure. In the second stage procedure, ceftriaxone $(1 \mathrm{mg} / \mathrm{ml})$ were mixed with AuNP ( $1 \mathrm{mg} / \mathrm{ml})$ in phosphate buffer solution, incubated for $24 \mathrm{~h}$, and collected at $12,000 \mathrm{~g}$ by ultracentrifugation for $10 \mathrm{~min}$ [21]. Freshly synthesized Cef-AuNP was dialyzed using a $10 \mathrm{kDa}$ cellulose membrane against double-distilled water overnight to remove any unreacted chemicals. Once dialyzed, the samples were freeze-dried. The Cef-AuNP were obtained and stored to further characterization.

\section{Characterization of AuNP and Cef-AuNP}

Nano-materials were characterized according to Harshiny, et al. [21].

UV-visible spectroscopy and analysis of UV-Vis spectra were done by using a double beam spectrophotometer (Shimadzu uv1650 pc spectrophotometer, Japan). The solutions of AuNP and Cef-AuNP were monitored by measuring the UV-Vis spectrum of the solution in the wavelength range $300-800 \mathrm{~nm}$. The solution of nanoparticles was poured into a test tube and diluted four times with MilliQ water. Finally, it was analyzed at room temperature.

\section{Transmission Electron Microscopy (TEM)}

The TEM technique was used to show the size and shape of the Cef-AuNP and AuNP. The TEM (model JEOL 100CX II with an accelerating voltage of $100 \mathrm{kV}$, at Electron Microscope Unit, Assiut) was used to determine the TEM image. The sample was prepared by the piping of aqueous Cef-AuNP or AuNP sample drops on carbon-coated copper grids. Then the film on the grid was dried.

\section{Fourier Transform Infrared Spectroscopy (FT-IR)}

Petal extract powder, AuNP, ceftriaxone, and Cef-AuNP were prepared by centrifuging the solution of nano-materials at $15,000 \mathrm{~g}$ for $10 \mathrm{~min}$. The residue of previous products was washed with bi- distilled water to remove any unattached biological materials from the surface of the nanoparticles. Each residue was then dried, and the powder was used for measurement of FT-IR, which was detected in the 4,000-500 $\mathrm{cm}^{-1}$ region with a spectrometer (Shimadzu IR-470, Japan). The one hundred milligrams dried sample was mixed with $100 \mathrm{mg}$ of grade $\mathrm{KBr}$ and pressed into discs under hydraulic pressure. The FT-IR peaks were identified and expressed in wavenumbers $\left(\mathrm{cm}^{-1}\right)$.

\section{Determination of Conjugating Efficiency of Cef-AuNP}

Conjugating efficiency of Cef-AuNP was calculated as Shaker and Shaaban [22]. The Cef-AuNP were centrifuged for $10 \mathrm{~min}$ at $12,000 \mathrm{~g}$. Free ceftriaxone drug in the supernatant was quantified by the same aforementioned double beam spectrophotometer ( $\lambda$ max 330) obtained from wave scan [21]. The calibration curve of ceftriaxone antibiotic was schemed in the linear range of 10$100 \mathrm{mg} / \mathrm{ml}$. We needed to find out the amount of ceftriaxone attached to the AuNP to calculate the percentage of ceftriaxone conjugating efficiency. For this, we took out the free drug remaining in the supernatant (or the drug not attached to the AuNP) from the initial amount of ceftriaxone added and used the following equation:

Conjugating efficiency $(\%)=($ Total amount of ceftriaxone - Free ceftriaxone in the supernatant/Total amount of ceftriaxone) $\times 100$.

\section{Antibacterial Activity of Cef-AuNP Using Well Agar Diffusion Method}

The AuNP and Cef-AuNP solutions were tested for their antibacterial efficacy against studied ESBL-producing bacteria using the well agar diffusion method [23]. The pathogens cultures were initially inoculated in nutrient broth medium followed by incubation at $37^{\circ} \mathrm{C}$ for $18 \mathrm{~h}$. The overnight-grown cultures were then again sub-cultured into a nutrient broth for $2 \mathrm{~h}$ till 0.01 optical densities. Thus, $100 \mu \mathrm{l}$ of each bacterial culture was distributed onto the surface of nutrient agar medium and wells of six mm were made on nutrient agar plates. Ceftriaxone, AuNP and CefAUNP with different concentration were pipetted into the wells and the plates were incubated at $37^{\circ} \mathrm{C}$ for $24 \mathrm{~h}$. The inhibition zone was detected by recording the diameter of clear area around each well.

Determination of Minimum Inhibitory Concentration (MIC) and Minimum Bactericidal Concentration (MBC) of Cef-AuNP

The MIC evaluation was performed on a 96 well plate. Two hundred $\mu \mathrm{l}$ of AuNP or Cef-AuNP were piped into the 6 wells in column 1. One hundred $\mu \mathrm{l}$ of broth growth medium for each strain was piped into the wells in each row. Thereafter, $100 \mu \mathrm{l}$ of the AuNP or Cef-AuNP solution was taken from column 1 and was serially diluted along the row until column number 10 . Thereafter, $5 \mu$ of the bacterial cultures was piped into each well containing the suitable medium except column number 10, which was considered as blank. Moreover, $50 \mathrm{ml}$ of phenol red dye $(2 \mathrm{mg} / \mathrm{ml})$ was pipetted in each well to estimate the viability of 
bacteria. The plate of 96-well was incubated and red color of bacterial cell viability was detected after an incubation time of $24 \mathrm{~h}$ at $37^{\circ} \mathrm{C}$. The inhibition of growth was detected as no color was shown in the well. The minimum concentration of Cef-AuNP at which no growth or no color was observed has been considered as MIC value. However, after inoculation of five $\mu \mathrm{l}$ from each well on the surface of agar medium plates, minimum bactericidal concentration $(\mathrm{MBC})$ was evaluated. The incubation of bacterial culture plates was obtained at $37^{\circ} \mathrm{C}$ for $24 \mathrm{~h}$. Finally, the agar medium plates were examined for growth or no growth. The wells containing the minimum concentration of test solutions, showing no growth, were declared as the MBC [24].

\section{Anticancer Activity}

Maintenance of cell cultures. The MCF-7 cells (ATCC HB8065, Manassas, VA) used in this study were obtained from Collection of American Type Culture by National Research Center-Egypt. The human breast cancer MCF-7 cell line was kindly provided by Dr. Khaled Fekry -National Research Center-Egypt. The MCF-7 cells were propagated and maintained in Eagles Minimum Essential Medium (EMEM) supplemented with $(10 \%, v / v)$ Fetal Bovine Serum at $37^{\circ} \mathrm{C}$ in a $\mathrm{CO}_{2}$ incubator $\left(100 \%\right.$ relative humidity, $5 \% \mathrm{CO}_{2}$, and $95 \%$ air). The cells were harvested after brief trypsinization.

Trypan blue dye exclusion assay. The influence of biosynthesized AuNP and Cef-AuNP on the viability of MCF-7 cancer cells were evaluated and analyzed using the trypan blue dye exclusion assay. The cells were seeded $\left(0.5 \times 10^{5}\right.$ cells $\left./ \mathrm{ml}\right)$ in six-well plates in complete medium. The MCF-7 cells were mixed with $0.1 \mu \mathrm{g} / \mathrm{ml}$ of each treatment (AuNP and Cef-AuNP). Additionally, different times were used for incubation the MCF-7 cells, these times were 24,48 , and $72 \mathrm{~h}$. After the periods of incubation, the cultures of MCF-7 human cancer cell line were harvested, washed, and suspended with phosphate buffered saline (PBS and 0.4\% trypan blue) in preparation for the next step. Finally, the hemocytometer apparatus was used for counting the MCF-7 cancer cells [25] and each experiment was carried out in three replications.

MTT assay. In order to evaluate the cytotoxicity of AuNP and Cef-AuNP, the MCF-7 cells were collected in the exponential phase of growth followed by seeding into 96 well tissue culture plates. Additionally, the adherence of cells was allowed for $24 \mathrm{~h}$. Thereafter, $0.1 \mu \mathrm{g} / \mathrm{ml}$ of each AuNP or Cef-AuNP concentration was piped to the desired wells and incubated for $48 \mathrm{~h}$. After incubation, $20 \mu \mathrm{l}$ of the Eagle's Minimum Essential Medium (EMEM) containing MTT (3 [4,5dimethylthiazol2yl] 2,5diphenyltetrazolium bromide) $(5 \mathrm{mg} / \mathrm{ml})$ was piped to each well and incubated for $4 \mathrm{~h}$ at $37^{\circ} \mathrm{C}$. Next, the EMEM medium was changed with $100 \mu \mathrm{l}$ of dimethyl sulfoxide (DMSO) [26]. The viability of MCF-7 human cancer cells was detected by the appearance of the purple color indicating formazan crystal formation. The optical densities were measured at wavelength $570 \mathrm{~nm}$. All experimental measurements of optical densities were determined in triplicate and expressed as the mean standard deviation.

\section{DNA Fragmentation Assay}

The fragmentation assay of DNA was carried out using agarose gel electrophoresis. After $72 \mathrm{~h}, \mathrm{AuNP}$ and Cef-AuNP treated cells were harvested by centrifugation. The cell pellets were mixed with lysis buffer $(100 \mathrm{ml})$ followed by incubation for $1 \mathrm{~h}$ at $50^{\circ} \mathrm{C}$. Proteinase $\mathrm{K}(10 \mu \mathrm{l})$ was added and incubated for $30 \mathrm{~min}$ at $50^{\circ} \mathrm{C}$. Three microliters of RNase enzyme was then added and incubated for $2 \mathrm{~h}$ at $50^{\circ} \mathrm{C}$. The DNA was extracted using isoamyl alcohol: chloroform: phenol (25:24:1) and 2.5 volumes of absolute ethanol. Two percentage of agarose gel was used and stained with ethidium bromide dye. The fragmentation was observed using UV white light transilluminator.

\section{Gene Expression Analysis for Apoptotic Related Genes}

Using the manufacturer's protocol, TRIZOLA reagent (Invitrogen, USA) was used for extracting the total RNA from control and treated MCF-7 cultured cells. The first strand cDNA formation was performed using the reverse transcription Maxime RT PreMix kit.

Bax and TNF-a gene expression was determined using reverse transcription-polymerase chain. Next, the PCR amplification reactions were performed using the PXE 0.5 Thermo thermal cycler apparatus. The initial denaturation step of PCR amplification reactions were performed for $5 \mathrm{~min}$ at $95^{\circ} \mathrm{C}$; then 35 cycles at $95^{\circ} \mathrm{C}$ for $30 \mathrm{sec}$ (denaturing); at $55^{\circ} \mathrm{C}$ for $40 \mathrm{sec}$ (annealing), and at $72^{\circ} \mathrm{C}$ for $1 \mathrm{~min}$ (extension); and a further extension at $72^{\circ} \mathrm{C}$ for $7 \mathrm{~min}$. The gel bands were stained with ethidium bromide dye, scanned, and the signal intensities were quantified by a densitometer. The ratio between the levels of the GAPDH (housekeeping gene) and target genes-amplification product was calculated to normalize for initial variation in sample concentration as a control for reaction efficiency $[27,28]$.

\section{Statistical Analysis}

All experiments were carried out three times. Results were represented as means \pm standard deviation (S.D). The Statistical Package for Social Science (SPSS, version 11.0) was used to perform statistical analyses. One-way ANOVA (Analysis of Variance) was used to compare different time intervals of exposure to the same dose of treatment and $p<0.05$ was considered as statistically significant.

\section{Results and Discussion}

\section{Biosynthesis of AuNP}

The Rosa damascenes petal extract was added to gold chloride solution. After this step, the mixture color changed from colorless to wine-red within $30 \mathrm{~min}$. This indicated the formation of the AuNP, as shown in Fig. 1 due to the fabrication of AuNP with the biological reducing agents present in the Rosa damascenes petal extract. The biological reducing agents in Rosa damascenes petal extract reduced 


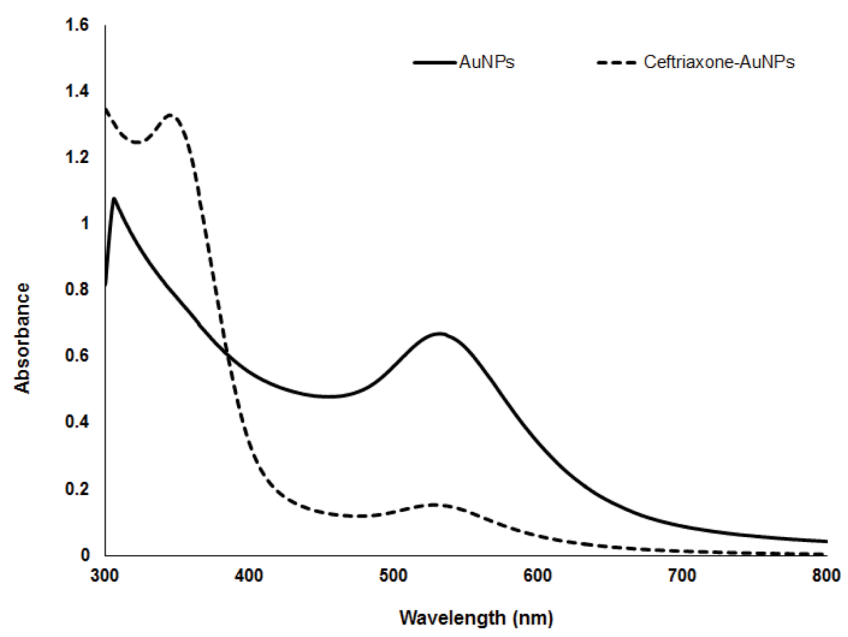

Fig. 1. UV-Vis spectrophotometry analysis of AuNP and Ceftriaxone-AuNP.

the gold ions to AuNP. The Rosa damascenes petals are known to contain a rich extract of phenolic compounds that are used as biological reducing agents. The AuNP aqueous solution appeared to have a wine-red color due to the excitation of surface plasmons. Samples of AuNP were removed and analyzed by using UV visible-spectroscopy for the confirmation of AuNP formation at regular time intervals. It was noticed that the complete color change took about $1 \mathrm{~h}$, thereafter no further change occurred in the color of the reaction mixture. This indicated the complete reduction of $\mathrm{HAuCl}_{4}$ in the reaction mixture. The protection, stability, and reductive activity of plant biomolecules accounted for the reduction of gold ions [29]. They have advantages over other metal nanoparticles (MNPs) for being biocompatible and possessing a non-toxic nature [30].

\section{The Formation of Biosynthesized AuNP Conjugated with Ceftriaxone}

Ceftriaxone has a carboxylate group through which it can absorb (sp) into the amino group of the AuNP surface [31]. UV-Vis absorption was also studied after the formation of AuNP and ceftriaxone conjugates; Cef-AuNP were dispersed and absorbance was measured by using UV-visible spectrophotometer between 300 and $800 \mathrm{~nm}$. The CefAuNP showed peaks at $330 \mathrm{~nm}$ and $530 \mathrm{~nm}$ while The UVvisible peak at $530 \mathrm{~nm}$ was for pure AuNP (as shown in Fig. 1).

\section{Transmission Electron Microscope Analyses}

The AuNP, as well as the Cef-AuNPs were characterized

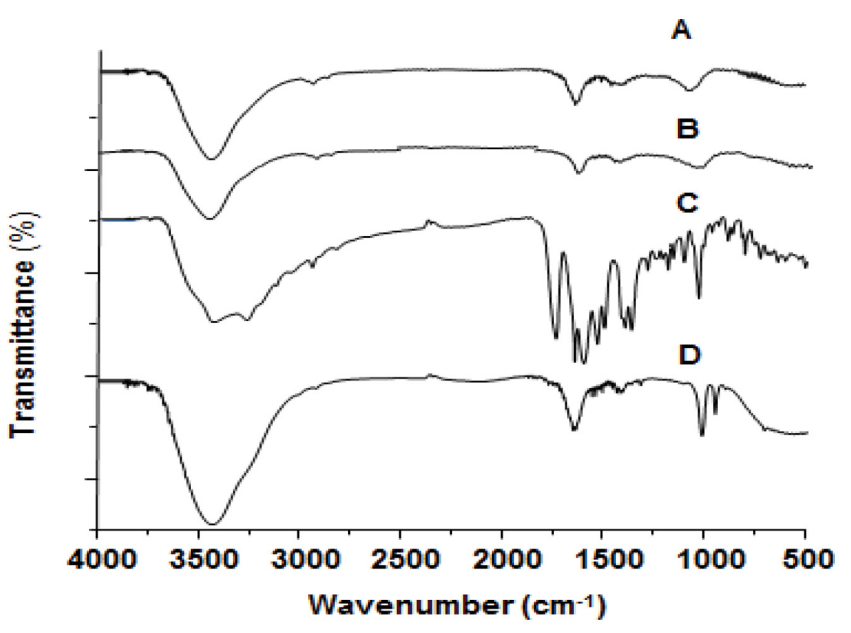

Fig. 2. FTIR analysis of Rosa damascenes petals extracts (A), AuNPs (B), Ceftriaxone (C), and Ceftriaxone-AuNPs (D).

using TEM analysis (Figs. 2A and 2B) and the size of the AuNP and Cef-AuNP were determined to be at 14.2$25.3 \mathrm{~nm}$ and $26.6-45.8 \mathrm{~nm}$, respectively. These results suggested that there was an increase in the size of the AuNP due to the attachment of ceftriaxone to the AuNP and these results agree with Shaikh et al. [32]. TEM analysis showed that all these AuNP were of spherical, hexagonal, and triangular shape.

\section{Comparison of FTIR Spectra of Rosa damascenes Petal Extract, AuNP, Ceftriaxone, and Cef-AuNP}

The FTIR were displayed in the mid-infrared region (MIR) within the range $\left(500-4,000 \mathrm{~cm}^{-1}\right)$, as shown in Fig. 3. The FTIR analysis further confirmed the presence of functional groups representing bioactive compounds of Rosa damascenes extract through the absorption bands at $3,438 \mathrm{~cm}^{-1}$, implying $\mathrm{OH}$ stretching, 1,631 $\mathrm{cm}^{-1}$, denoting a carbonyl group, $1,409 \mathrm{~cm}^{-1}$, representing the $\mathrm{C}-\mathrm{N}$ bond and $1,042 \mathrm{~cm}^{-1}$ of $\mathrm{C}-\mathrm{N}$ stretch as shown in Fig. 3A. Au metal ions caused a reduction in the absorbance intensities at $3,437 \mathrm{~cm}^{-1}$, representing $\mathrm{OH}$ stretching. Absorbance peak at $1,631 \mathrm{~cm}^{-1}$ (carbonyl groups), $1,425 \mathrm{~cm}^{-1}$ (C- N stretching vibrations), $1,019 \mathrm{~cm}^{-1}$ (C-O) and $543 \mathrm{~cm}^{-1}$ (-CH- stretch) have shown that organic compounds in the plant extract have stabilized AuNP, thereby preventing agglomeration (Fig. 3B). Ceftriaxone conjugation was also confirmed by FTIR spectroscopy (Fig. 3C). The absorption peaks that appeared in the FTIR spectrum of ceftriaxone were 3,425, 3,255 , and $2,796 \mathrm{~cm}^{-1}$ which could be assigned to the stretching vibrations of $\mathrm{N}-\mathrm{H}, \mathrm{O}-\mathrm{H}$, and $\mathrm{C}-\mathrm{H}$ groups, respectively. The stretching vibrations of carbonyl groups, 


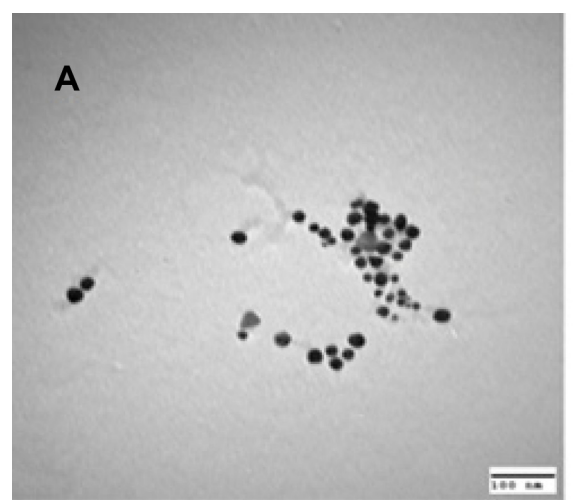

Fig. 3. TEM analysis of (A) AuNP and (B) Ceftriaxone-AuNP.

$\mathrm{C}-\mathrm{N}, \mathrm{C}-\mathrm{O}$ and $=\mathrm{C}-\mathrm{H}$ appeared at 1,657, 1,356, 1,030, and $750 \mathrm{~cm}^{-1}$, respectively. The vibration modes of $\mathrm{C}-\mathrm{O}$ and $\mathrm{C}-\mathrm{C}$ groups were represented by the absorption peaks in the region from 600 to $500 \mathrm{~cm}^{-1}$, respectively [21].

As shown in (Fig. 3D), the conjugation of ceftriaxone with AuNP resulted in merging and the reduction of bands $\mathrm{N}-\mathrm{H} 3,425 \mathrm{~cm}^{-1}, 1,657 \mathrm{~cm}^{-1}$ carbonyl groups, $1,356 \mathrm{~cm}^{-1} \mathrm{C}-\mathrm{N}$ and $1030 \mathrm{C}-\mathrm{O} \mathrm{cm}{ }^{-1}$ [21].

\section{Calculation of Conjugating Efficiency}

Conjugating efficiency is an important parameter in the estimation and characterization of nanoparticles conjugates. The ceftriaxone conjugating efficiency of AuNP was found to be $81.5 \%$. During preparation of ceftriaxone conjugated AuNP, a lesser amount is needed for therapeutic use because the conjugating efficacy should be high so that ceftriaxone is not lost $[22,31]$.

\section{Antibacterial Activity}

The antibacterial activities of the biosynthesized AuNP and Cef-AuNP were studied by a qualitative well agar diffusion assay on both bacteria. Table 2 showed the inhibition zone (ZOI) for each pathogenic strain. After18 $\mathrm{h}$ of incubation at $37^{\circ} \mathrm{C}$, the nutrient agar plates containing ceftriaxone, AuNP and Cef-AuNP conjugates exhibited a ZOI around 6-29 $\mathrm{mm}$. The control plates and ceftriaxone antibiotic devoid of AuNP did not exhibit any inhibition zones. P. aeruginosa and A. baumannii showed zones of inhibition of $6 \mathrm{~mm}$ for ceftriaxone, 6 and $7 \mathrm{~mm}$ respectively,

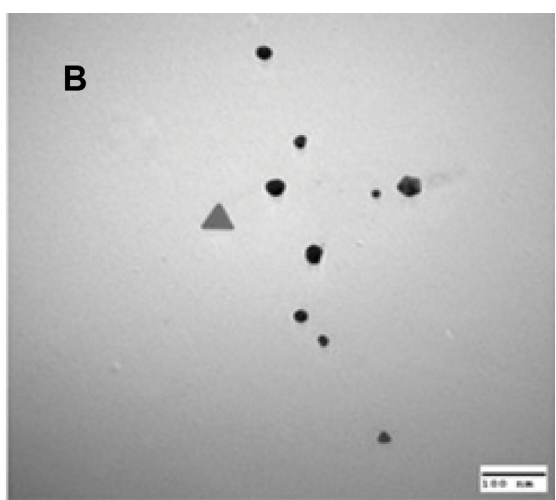

for AuNP, and $27 \mathrm{~mm}$ and $29 \mathrm{~mm}$ inhibition zones respectively, for Cef-AuNP. The results suggested that the Cef-AuNP were highly effective against bacterial strains compared to ceftriaxone and AuNP alone. Cef-AuNP conjugate exhibited greater antimicrobial efficiency against both bacteria strains.

\section{Minimum Inhibitory Concentration and Minimum Bactericidal Concentration (MIC and MBC) Assays}

MIC of Cef-AuNP was found as 3.6 and $4 \mu \mathrm{g} / \mathrm{ml}$ against the tested strains of $P$. aeruginosa, and $A$. baumannii respectively (Table 2). Moreover, MBC of Cef-AuNP was determined to be $16 \mu \mathrm{g} / \mathrm{ml}$ for each strain. CeftriaxoneAuNP significantly decreased the MICs of ceftriaxone against $P$. aerugnosa and $A$. baumannii by more than 27 times. Because of the unique physiochemical properties of AuNP, such as biocompatibility and non-cytotoxicity, they have been used as drug delivery tools in various studies [33]. Additionally, conjugation ampicillin and carbapenems with AuNP retained its activity and showed potent effect against multi-drug resistant bacteria while AuNP alone were non-toxic $[22,34]$. In the same way, our data also indicate that ceftriaxone retain its activity after conjugation to AuNP because unconjugated gold nanoparticles were inactive against the tested drug resistant strains.

\section{Mechanism of Overcoming Resistance by Ceftriaxone- AuNP (Hypothesis)}

Fig. 4 shows TEM of P. aeruginosa treated with $3.6 \mu \mathrm{g} / \mathrm{ml}$

Table 2. Antimicrobial activity of ceftriaxone drug, gold nanoparticles and ceftriaxone-AuNP conjugates.

\begin{tabular}{ccc}
\hline Bacteria & \multicolumn{2}{c}{ Zone of inhibition for $1 \mu \mathrm{gg} / \mathrm{ml}$ sample } \\
\cline { 2 - 3 } Acinetobacter baumannii ACI1 & ceftriaxone & AuNP \\
\hline Pseudomonas aeruginosa PSE4 & $6 \mathrm{~mm}$ & $6 \mathrm{~mm}$ \\
\hline
\end{tabular}


Table 3. Minimum Inhibitory Concentration (MIC) and Minimum Bactericidal Concentration (MBC) of Ceftriaxone-AuNP against ESBL Positive P. aeruginosa and A. baumannii.

\begin{tabular}{cccc}
\hline \multirow{2}{*}{ Bacteria } & Ceftriaxone & \multicolumn{2}{c}{ Ceftriaxone-AuNP } \\
\cline { 2 - 4 } & MIC & MIC & MBC \\
\hline Acinetobacter baumannii ACI1 & $>100 \mu \mathrm{g} / \mathrm{ml}$ & $4 \mu \mathrm{g} / \mathrm{ml}$ & $16 \mu \mathrm{g} / \mathrm{ml}$ \\
Pseudomonas aeruginosa PSE4 & $>100 \mu \mathrm{g} / \mathrm{ml}$ & $3.6 \mu \mathrm{g} / \mathrm{ml}$ & $16 \mu \mathrm{g} / \mathrm{ml}$ \\
\hline
\end{tabular}

Cef-AuNP. Conjugated nanoparticles accumulated both in the cell walls of bacteria and inside the cell themselves. Regarding the resistance-overcoming mechanism in this particular piece of work, we could propose the following hypothesis. The effective concentration of ceftriaxone delivered to the bacterial cell was increased due to its binding to AuNP. This caused two-way damage to bacteria. The first way could be genuinely expected to be due to the increased presence of ceftriaxone molecules per unit volume of the system, that is, the ceftriaxone molecules which remained untouched by the bacterial enzyme. Ceftriaxone works by inhibiting the mucopeptide formation in the bacterial cell wall $[35,36]$. The cell membrane disruption caused by the drug results in leakage of the cytoplasmic content, lysis, and death of the bacterial cell. Increased porosity of the membrane contributed to the secondary damage to the cell membrane [17]. Once CefAuNP enter the bacteria they easily interrupt all of the membrane's regulatory functions, effectively inactivating the bioactive blockage of protein synthesis, sulfur containing

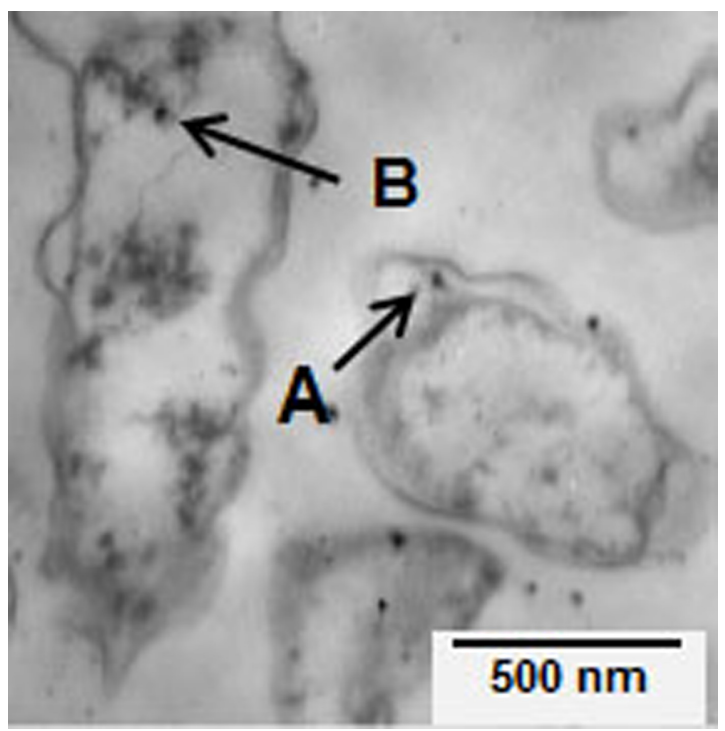

Fig. 4. TEM analysis of $P$. aeruginosa after exposure to Ceftriaxone-AuNP, and its accumulation in cell wall (A) and inside the cell (B). proteins, and interaction with the phosphorous in the nucleic acid (i.e., RNA and DNA) structure [35, 36].

\section{Anticancer Activity}

The applications of metal nanoparticles in the medical field have been confirmed for the diagnosis and treatment of various types of tumors and other common diseases. AuNP based on biological Rosa damascenes extract molecules are new and have revolutionized the treatment of malignant deposits and do not interfere with the normal cells. In the present study, the cytotoxic effect of AuNP, and Cef-AuNP on MCF-7 human breast cancer cells showed that the biosynthesized AuNP demonstrated cytotoxicity and a direct time-response relationship against the MCF-7 cells. This was also enhanced by increasing the exposure time. The maximum inhibition of growth and decrease in viability appeared in MCF-7 cells treated with AuNP for $72 \mathrm{~h}$ at a dose $0.1 \mu \mathrm{g} / \mathrm{ml}$ (as shown in Table 4). This exposure time was selected for further studies. The results obviously reveal that AuNP induce cytotoxicity in the MCF-7 cancer cells in a time dependent manner. This shows that it effectively inhibits the MCF-7 cells growth by 20.3, 33.2, and $48.3 \%$ for 24,48 , and $72 \mathrm{~h}$, respectively, while causing the loss of viability.

There were also morphological changes in MCF-7 presented by cell shrinkage, blebbing and pyknotic nuclei when the cell treated with AuNP for $72 \mathrm{~h}$ compared to cells treated with Cef-AuNP and a significant decrease in the cellular crowding was seen in comparison to the normal attached MCF-7 human breast cancer cells as shown in Fig. 5. However, a typical apoptotic appearance of MCF-7 breast cancer cells, such as apoptotic bodies, fragmented nuclei, and chromatin condensation, were observed in a time-dependent manner and the changes in appearance were most obvious after $72 \mathrm{~h}$ of both treatments. In this concern, Mohseni et al. [37] reported that AuNP were significantly toxic to the MCF-7 cells at the concentration of $2.50 \mathrm{mg} / \mathrm{ml}$ and higher and this result was in agreement with the present result. Various studies reported that plant derived AuNP have a potency to control tumor cell growth. The improved AuNP cytotoxic efficacy is due to 
Table 4. Effect of AuNP and Cef-AuNP treatment on the proliferative and viability percentage of MCF-7 cultured cells at different exposure times.

\begin{tabular}{|c|c|c|c|c|c|c|}
\hline \multirow{2}{*}{$\begin{array}{l}\text { Treatment } \\
0.1 \mu \mathrm{g} / \mathrm{ml}\end{array}$} & \multicolumn{3}{|c|}{ Proliferative percentage of MCF-7 cells at different times } & \multicolumn{3}{|c|}{ Viability $\%$ of MCF-7 Cells at different exposure times } \\
\hline & $24 \mathrm{~h}$ & $48 \mathrm{~h}$ & $72 \mathrm{~h}$ & $24 \mathrm{~h}$ & $48 \mathrm{~h}$ & $72 \mathrm{~h}$ \\
\hline PBS & $93.0 \pm 1.73 \mathrm{a}$ & $92.4 \pm 0.67 \mathrm{a}$ & $94.2 \pm 3.33 \mathrm{a}$ & $85.0 \pm 1.75 \mathrm{a}$ & $87.7 \pm 1.35 \mathrm{a}$ & $84.8 \pm 1.43 \mathrm{a}$ \\
\hline AuNPs & $79.7 \pm 1.54 \mathrm{c}$ & $66.8 \pm 2.86 \mathrm{c}$ & $51.7 \pm 2.66 \mathrm{c}$ & $70.9 \pm 1.45 \mathrm{c}$ & $59.8 \pm 1.37 \mathrm{c}$ & $48.3 \pm 1.42 c$ \\
\hline Cef-AuNPs & $85.8 \pm 2.34 b$ & $80.4 \pm 1.73 b$ & $73.5 \pm 2.14 b$ & $78.0 \pm 1.38 \mathrm{~b}$ & $74.7 \pm 1.9 b$ & $69.5 \pm 2.33 b$ \\
\hline
\end{tabular}

Means with different superscripts ( $a, b$, and $c$ ) between groups in the same column are significantly different at $p<0.05$. Cell numbers were counted and data are expressed as the percentage of untreated control.

biological capping composition and other secondary metabolites in the synthesizing medium [38, 39].

The results displayed that the level of DNA fragmentation became more prominent when the MCF-7 cells treated with AuNP in comparison to control untreated cells (as shown in Figs. 5 and 6); while Cef-AuNP treatment induced a moderate anticancer activity and cytotoxic effects in comparison to the AuNP treated cells. The previous results were confirmed by Selim and Hendi [40] who reported the AuNP possess anticancer activity and cytotoxic effects against MCF-7 cancer cells. The moderate concentration of AuNP stimulated the apoptosis mechanism in the malignant cells [41].

Finally, AuNP were prepared from Rosa damascenes petal extract with a small-sized hexagonal, triangular, and spherical shapes. In this study, we examined the efficacy of using AuNP as ceftriaxone delivery system for the control of multi-drug resistant respiratory tract infections. These Cef-AuNP showed greater antimicrobial activity against ESBL-producing bacteria strains, $P$. aeruginosa and $A$. baumannii bacteria isolated from the sputum. In this study, antibacterial assays displayed that ceftriaxone after attachment with AuNP got "revived" and ESBL producing bacterial strains which were completely resistant to ceftriaxone turned sensitive to the Cef-AuNP. The ceftriaxone-AuNP might be used as an alternative of antimicrobial agents to ESBL producing bacteria. In future study we will come up with fresh nano-dugs of old antibiotics to control drug resistance bacteria, that is, "regeneration" of old antibiotics so as to keep pace with the decreasing stock of antibiotics. Our data confirmed that biosynthesized AuNP decrease the development of MCF-7

(1)
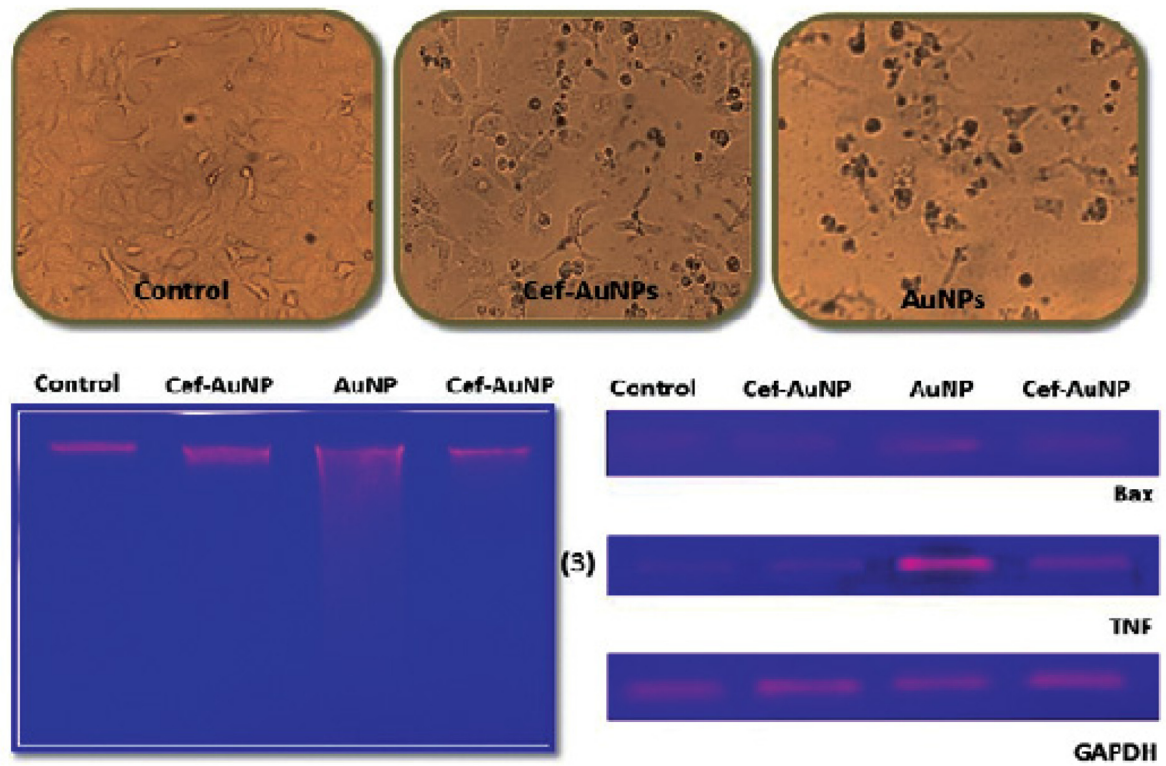

Fig. 5. Effect of various treatments of biosynthesized gold nanoparticles and Ceftriaxone-AuNP on MCF-7 cells treated for $72 \mathrm{~h}$ showing: (1) Morphological changes of MCF-7 cells using inverted microscope (2) DNA fragmentation evaluated by agarose gel electrophoresis and (3) Agarose gel electrophoresis of Bax, TNF and GAPDH RT-PCR products. 
A DNA fragmentation $\%$

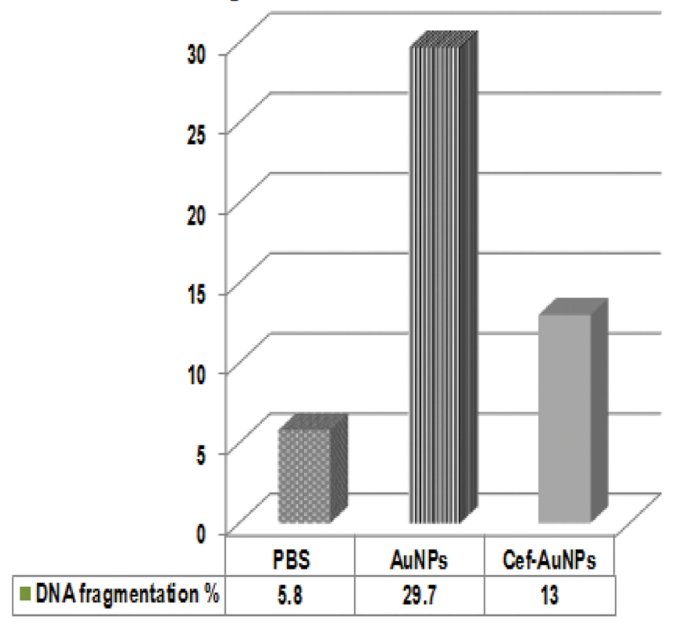

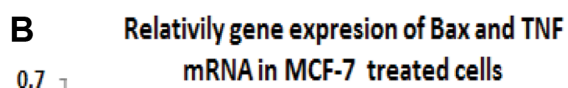

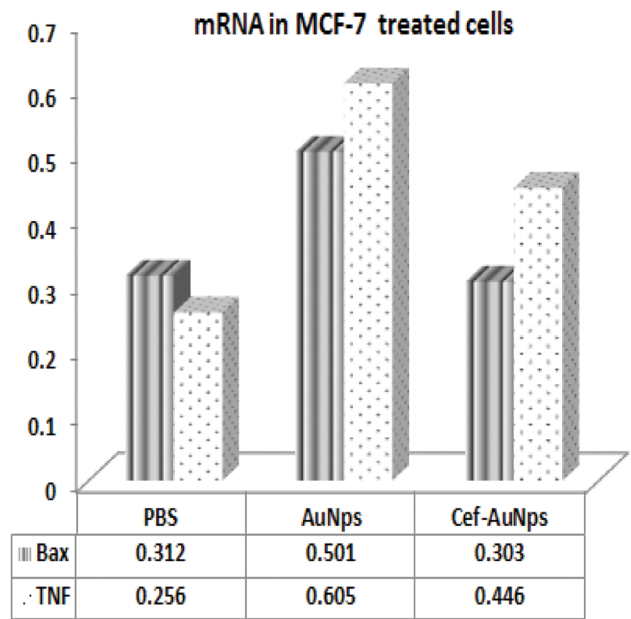

Fig. 6. Histograms represent the effect of various treatments of biosynthesized nanoparticles for $72 \mathrm{~h}$ on: (A) DNA fragmentation percentage in MCF-7 treated cells (B) Agarose gel electrophoresis of Bax, TNF and GAPDH RT-PCR products in MCF-7 cells after different treatments.

cancer cells in vitro through a remarkable increase in cell apoptosis. AuNP would be an amazing invention in the scope of nanomedicine.

\section{Acknowledgment}

We would like to express our gratitude to El-Edwani hospital for providing with us the samples and Taif University for financial support, under the project number $(1 / 437 / 5264)$.

\section{Conflict of Interest}

The authors have no financial conflicts of interest to declare.

\section{References}

1. Litake GM GV, Niphadkar KB and Joshi SG. 2015. Phenotypic ESBL detection in Acinetobacter baumannii: a real challenge. Am. J. Infect. Dis. 11: 48-53.

2. LB R. 2010. Progress and challenges in implementing the research on ESKAPE pathogens. Infect. Control Hospital Epidemiol. 31: S7-S10.

3. Centers for Disease Control and Prevention (CDC). Antibiotic resistance threats in the United States. Atlanta. GA. 2013.

4. Paterson DL BR. 2005. Extended-spectrum beta-lactamases: a clinical update. Clin. Microbiol. Rev. 18: 657-686.

5. Mishra SK RB, Pokhrel BM. 2013. Emerging threat of multidrug resistant bugs-Acinetobacter calcoaceticus baumannii complex and methicillin resistant Staphylococcus aureus. BMC Res. Notes 6: 98-103.

6. Shaikh S FJ, Shakil S, Rizvi SMD, Kamal MA. 2015. Prevalence of multidrug resistant and extended spectrum beta-lactamase producing Pseudomonas aeruginosa in a tertiary care hospital. Saudi J. Biol. Sci. 22: 62-64.

7. Yares R. 1999. New intervention strategies for reducing antibiotic resistance. Chest 115: 245-275.

8. Prat C LA. 2016. Bacteria in the respiratory tract-how to treat? Or do not treat? Int. J. Infect. Dis. 51: 113-122.

9. Sengstock DM TR, Apalara J, Mira A, Chopra T, Kaye KS. 2010. Multidrug-resistant Acinetobacter baumannii: an emerging pathogen among older adults in community hospitals and nursing homes. Clin. Infect. Dis. 50: 1611-1616.

10. Albrecht MA EC, Raston CL. 2006. Green chemistry and the health implications of nanoparticles. Green Chem. 8: 417-432.

11. Arachchige MC RY, Andreev OA. 2015. Advanced targeted nanomedicine. J. Biotechnol. 20: 88-97.

12. Anand K GR, Phulukdaree A, Chuturgoon A. . 2015. Agroforestry waste Moringa oleifera petals mediated green synthesis of gold nanoparticles and their anti-cancer and catalytic activity. J. Ind. Eng. Chem. 21: 1105-1111.

13. Patil MP KG. 2017. Eco-friendly approach for nanoparticles synthesis and mechanism behind antibacterial activity of silver and anticancer activity of gold nanoparticles. Appl. Microbiol. Biotechnol. 101: 79-92.

14. Raghunandan D RB, Sharanbasava G, Mahesh DB, Harsoor V, Yalagatti MS, Bhagawanraju M, et al. 2011. Anti-cancer studies of noble metal nanoparticles synthesized using different plant extracts. Cancer Nanotechnol. 2: 57-65.

15. Biju V. 2014. Chemical modifications and bioconjugate 
reactions of nanomaterials for sensing, imaging, drug delivery and therapy. Chem. Soc. Rev. 43: 737-962

16. Demurtas M PC. 2014. Facile one-pot synthesis of amoxicillincoated gold nanoparticles and their antimicrobial activity. Gold Bull. 47: 103-107.

17. Cui Y ZY, Tian Y, Zhang W, Lü X, Jiang X. 2012. The molecular mechanism of action of bactericidal gold nanoparticles on Escherichia coli. Biomaterials 33: 2327-2333.

18. Gad El-Rab SMF HE, Elzahrani S. 2018. Synthesis of Rifampicin conjugated gold nanoparticled and antimicrobial application against MDR Pseudomonas aeruginosa. Res. J. Biotechnol. (In Press).

19. Garza-Navarro MA A-RJ, Llanas-Vázquez EE, MorenoCortez IE, Torres-Castro A, González-González V. 2013. Totally Ecofriendly synthesis of silver nanoparticles from aqueous dissolutions of polysaccharides. Int. J. Polym. Sci. 2013: 1-8.

20. Yu J XD, Guan HN, Wang C, Huang LK. 2016. Facile onestep green synthesis of gold nanoparticles using Citrus maxima aqueous extracts and its catalytic activity. Mater. Lett. 166: 110-112.

21. Harshiny M MM, Arthanareeswaran G, Kumaran S, Rajasree S. 2015. Enhancement of antibacterial properties of silver nanoparticles- ceftriaxone conjugate through Mukia maderaspatana leaf extract mediated synthesis. Ecotoxicol. Environ. Saf. 121: 135-141.

22. Shaker MA SM. 2017. Formulation of carbapenems loaded gold nanoparticles to combat multi-antibiotic bacterial resistance: in vitro antibacterial study. Int. J. Pharmaceutics 525: 71-84.

23. Kanmani P LS. 2013. Synthesis and characterization of pullulan-mediated silver nanoparticles and its antimicrobial activities. Carbohydr. Polym. 97: 421-428.

24. Pani A LJ, Yun S. 2016. Autoclave mediated one-pot-oneminute synthesis of AgNPs and Au-Ag nanocomposite from Melia azedarach bark extract with antimicrobial activity against food pathogens. Chem. Cent J. 10: 15.

25. Szende B TE, Trezl L. 2001. Role of arginine and its methylated derivatives in cancer biology and treatment. Cancer Cell Int. 17: 1-3.

26. Horiuchi N NK, Sasaki Y, Minato K, Fujiwara Y, Nezu K, et al. 1998. In vitro antitumor activity of mitomycin $C$ derivative (RM- 49) and a new anticancer antibiotic (FK973) against lung cancer cell lines determined by tetrazolium dye (MTT) assay. Cancer Chemother. Pharmacol. 22: 246-250.

27. Brun ME GS, Girard C, Bouton K, De Massy B, De Sario A. 2006. Characterization and expression analysis during embryo development of the mouse ortholog of MLL3. Gene 371: 25-33.

28. Hassan AM A-AS, Abdel-Wahhab MA. 2012. Modulation of DNA damage and alteration of gene expression during aflatoxicosis via dietary supplementation of Spirulina (Arthrospira) and whey protein concentrate. Ecotoxicol.
Environ. Saf. 79: 294-300.

29. Du J ZZ, Zhang X, Wu S, Xiong J, Wang W, Luo Q 2017. Biosynthesis of gold nanoparticles by flavonoids from Lilium casa blanca. J. Cluster Sci. 28: 3149-3158.

30. Yang N WL, Hao L. 2014. Biosynthesis of Au nanoparticles using agricultural waste mango peel extract and its in-vitro cytotoxic effect on two normal cells. Mat. Lett. 134: 67-70.

31. Zaki NM HM. 2012. Enhanced antibacterial effect of ceftriaxone sodium-loaded chitosan nanoparticles against intracellular Salmonella typhimurium. AAPS Pharm. Sci. Tech. 13: 411-421.

32. Shaikh S RS, Shakil S, Hussain T, Alshammari TM, Ahmad W, Tabrez S, et al. 2017. Synthesis and characterization of cefotaxime conjugated gold nanoparticles and their use to target drug-resistant CTX-M-producing bacterial pathogens. J. Cell. Biochem. 9999: 1-7.

33. Alkilany AM MC. 2010. Toxicity and cellular uptake of gold nanoparticles: what we have learned so far? J. Nanoparticle Res. 12: 2313-2333.

34. Brown AN SK, Samuels TA, Lu J, Obare SO, Scott ME. 2012. Nanoparticles functionalized with ampicillin destroy multipleantibiotic-resistant isolates of Pseudomonas aeruginosa and Enterobacter aerogenes and methicillin-resistant Staphylococcus aureus. Appl. Environ. Microbiol. 78: 2768-2774.

35. Grace AN PK. 2007. Quinolone antibiotic-capped gold nanoparticles and their antibacterial efficacy against gram positive and gram negative organisms. J. Bionanosci. 1: 96-105.

36. Kalita S KR, Sharma KK, Kataki AC, Deka M, Kotoky J. 2016. Amoxicillin functionalized gold nanoparticles reverts MRSA resistance. Mater. Sci. Eng. C Mater. Biol. Appl. 61: 720-727.

37. Mohseni N SF, Ardestani MS, Kazemi-Lomedasht F, Ghorbani M. 2016. Inhibitory effect of gold nanoparticles conjugated with interferon gamma and methionine on breast cancer cell line. Asian Pac. J. Trop. Biomed. 6: 173-178.

38. Das S DJ, Samadder A, Bhattacharyya SS, Das D, KhudaBukhsh AR. 2013. Biosynthesized silver nanoparticles by ethanolic extracts of Phytolacca decandra, Gelsemium sempervirens, Hydrastis canadensis and Thuja occidentalis induce differential cytotoxicity through G2/M arrest in A375 cells. Colloid Surf. B. 101: 325-336.

39. Raghunandan D BP, Bendegumble B, Bedre MD, Bhagawanraju M, Yalagatti MS. 2011a. Microwave-assisted rapid extracellular biosynthesis of silver nanoparticles using carom seed (Trachyspermum copticum) extract and in vitro studies. Am. J. Anal. Chem. 2: 475-483.

40. Selim ME HA. 2012. Gold nanoparticles induce apoptosis in MCF-7 human breast cancer cells. Asian Pacific J. Cancer Prev. 15: 9471-9473.

41. Dipankar C MS. 2012. The green synthesis, characterization and evaluation of the biological activities of silver nanoparticles synthesized from Iresine herbstii leaf aqueous extracts. Colloid. Surf. B. 98: 112-119. 